\title{
Towards a Definition of Educational Robotics
}

\author{
Julian M. Angel-Fernandez ${ }^{1}$ and Markus Vincze $^{1}$
}

\begin{abstract}
There is an increasing number of articles, web pages, robotic kits and other materials that are using the term Educational Robotics (ER) to refer to the use of robots in education, however the current definition of ER is still vague and open to misinterpretation. Therefore, anyone can claim that their work falls in the category of ER just because robots are involved. Despite all benefits of robotics, its incorrect use may be counterproductive. Therefore, the incremental use of the term ER is meaningless if it is not used correctly. Consequently, a concrete and precise definition of ER is required to support the development of it. This paper presents a first attempt to develop a concrete definition of ER, which describes all fields of study that constitutes it and how they are related between them. The definition is the result of the experience acquire during the participation of the European project Educational Robotics for STEM (ER4STEM).
\end{abstract}

\section{INTRODUCTION}

Robotics has been mentioned by many researchers as a technology with significant potential to impact education [1], [2], [3], [4]. This is reflected in the increasing number of articles that uses the words robotics and education together, such as is presented in Figure 1-a. Likewise, the use of Educational Robotics (ER) has increased in the last two decades, as it is presented in Figure 1-b. Despite its increment, there is not a clear definition of what ER is and in many situations is mentioned just as a tool used in education [5], [6], [7] or as a vehicle to think about teaching, learning and education at large [8]. If ER is a merely tool, then several questions arise: What is robots' role in this "tool"? Who is responsible to develop further this "tool"? Is there any difference between educational robotics, educational robots, robots in education and robots for education? On the other hand, if it is seen as a vehicle: who has created the vehicle? How should the vehicle look like? How is it used?

While these and other questions are still open, it is difficult to correctly coordinate and establish criteria to identify works that can be categorized as ER. For example in the work 5Step Plan [9], the researchers categorized their work as ER. However, they suggest that students are product designers that have to conceptualize a robot from scratch, without time nor knowledge to implement it. Then, participants could let their imagination go wild and come with creativity designs and tasks for their robots. In this case, robotics is used as a word to attract people's interest and not as a device to improve the learning experience. As a consequence, it could not be considered as ER because no robot is used to explain new concepts or strength others. Instead, it could be classified

\footnotetext{
${ }^{1}$ Julian M. Angel-Fernandez and Markus Vincze are with the Automation and Control Institute, Vienna University of Technology, Vienna, Austria Angel-Fernandez, Vincze\} Aacin.tuwien.ac.at
}

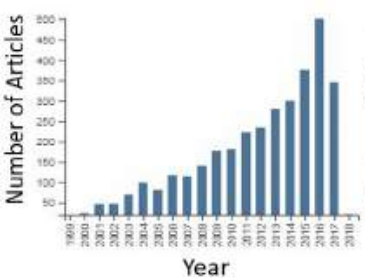

a)

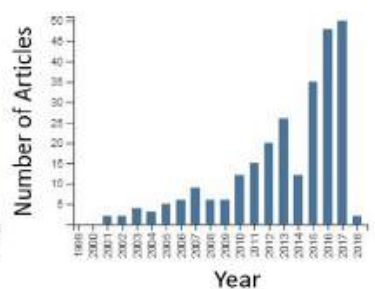

b)
Fig. 1. Total number of articles per year retrieved from Web of Science using the following queries: a) "Education* AND Robot *", which retrieves articles that contains any word derived from education and robot words, such as educational, robots, robotics, just to mention a few. Other words could be between these words and the order in which they appear does not matter. b) "Educational Robotics", which retrieve articles that contains the exact match of the words without other words in the middle.

as product design activity because participants learned the steps to correctly conceived and design a product, in this case a robot. However, this type of activities can create false or unreachable expectations of robots, which could frustrate people because current robots could not fulfill them. This frustration negatively affects the level and quality of the effort that people put into learning [10].

Despite all the benefits that robotics could have in fostering digital skills (e.g. programming [11]), STEM (e.g. Physics [12] and Mathematics [13]) and soft-skills (e.g. Creativity [14]), its incorrect use may be counterproductive [15] and it could stop its implementation in formal education settings (e.g. Schools). Therefore, a concrete definition, that specifies the meaning of ER is mandatory to correctly make move towards the right direction. This paper presents a first attempt to develop a concrete definition of ER, which describes components that constitute it and how they are related within them. The presented components are the result of the experience acquire during the participation in the European project Educational Robotics for Science, Technology, Engineering and Mathematics (ER4STEM) ${ }^{1}$, which aims at realizing a creative and critical use of ER to maintain children's curiosity in the world.

This paper is organized as follows. Section II presents some of the related in ER and Robotics in Education. With this as a base line and in order to have a better understanding of ER, an analysis of stakeholders involved in ER is presented in Section III. Considering their requirements and needs, Section IV describes the ideal activity

\footnotetext{
${ }^{1}$ www.er4stem.com
} 
in ER. Section V introduces the framework developed in ER4STEM, which aims to guide stakeholders in the design, implementation and evaluation of activities in ER. Based on the information presented, Section VI shows the field of studies that converge in ER and the definition of ER is provided. Finally conclusions are presented in Section VII.

\section{RELATED WORK}

Robotics is used in different settings and platforms. Sullivan and Bers [16] studied how robotics and computer programming could be used from pre-kindergarten to second grade classrooms and what children could learn from them. They developed an eight week curriculum focused on teaching foundations of robotics and programming concepts. The robotic platform KIWI was used, which was specifically designed for young children (four years and up). The main particularities of KIWI are that it could be programmed using the Creative Hybrid environment for computer Programming (CHERP) and it does not require any computer to be programmed [17]. Similarly, Stoeckelmayr et al. [18] created eight workshops to introduce robotic concepts to kindergarten students using BeeBot. These workshop are created from their experience in Robocup Junior.

Robotics can be also used to teach physics and mathematics. For example Church et al. [19] created and implemented activities to explain acceleration, speed, harmonic motion, pendulums and sound's variables. Ashdown and Doria [12] used robots to introduce the Doppler effect. Their results suggest that participants engaged with the activity and they learned about the proposed topic.

In the last decade, researchers have come with the idea of using social robots in schools. Some researchers have investigated the features that a robot should have when is placed in a classroom [20]. They identified that motion is important for the participants, because it helps to break the monotony of classroom. Moreover participants highlight the importance of visualizing geometrical concepts in the real world and their interest in interacting with the robot in petlike way. Other researchers focused on the impact of verbal cues given by a robot to participants [21], suggesting that it has a positive impact. Likewise Castellano et al. [22] as shown that people prefer robots that show empathy. These works are led by the Human Robot Interaction (HRI) community with especial focus on the social aspects of autonomous robots to improve the experience instead of the correct use of robots in education.

Despite the versatility of robotics in terms of topics, ages and situations, there is a missing understanding of ER to draw guidelines, scope and objectives. Without this understanding the real potential of robotics in education will not be completely unleashed and in some occasions, it could jeopardize the learning experience [15].

\section{STAKEHOLDERS IN EDUCATIONAL ROBOTICS}

In order to identify components that constitute ER to create a definition, it is required to understand who are the people involved, stakeholders, on it. ER4STEM's researchers [23] identified as stakeholders in ER:

- Young people are the ones who participate in ER activities offered by schools or other organizations. They are directly impacted by ER because are the ones who will participate in the activities created in ER.

- Young people parents may encourage their offspring to participate in activities or may not. Some parents would not be aware of the importance of digital skills [24], then they do not have any motivation to expose their offspring to activities that could foster them. This is an additional difficulty on the implementation of any ER because some parents would be hesitant to invest money and time.

- Schools are the place where formal teaching occurs and inside them two different stakeholders are present. (1) Teachers have as main responsibility to teach through the use of different methodologies. Although they are aware of the importance of Information and Communication Technologies (ICT) skills for teaching and new technologies [25], they are not confident about their knowledge in technology and its correct use in the classroom. (2) School boards or senior management decides over budget and established standards. They are influenced by the policymakers, government and parents.

- Organizations offering educational robotics which would be non-profit organizations offering ER activities, organizations based on profit or mixed versions (e.g. Clubs, projects, initiatives, universities, science and technology institutes). The activities offered by these organizations reach a wide audience and can create a big impact. Usually the activities offered by these institutions are considered as non-formal because are not link with any school curricula.

- Universities study, envision and developed technologies and techniques to be used in different fields, such as education and robotics. There are several stakeholders inside them that contribute in ER: educational researchers, teacher educators, engineering scientists and people involved in outreach programs. In many cases there is not much communication between them, which hinder the potential of ER.

- Industry is directly affected by people's skill sets and education. The demand in high quality knowledge workers in STEM fields is increasing worldwide but young people choosing STEM fields are not matching these numbers in demand [26]. There are even initiatives started by industry to counter these developments.

- Educational Policy makers are governmental organizations established with the purpose to lead the future of education.

ER does not have to address all of these stakeholder at once because covering all their requirements is a difficult task. Instead, ER, as a first step, must focus on those who have a direct impact on the quality of the activities, which 
results could be used to support the investment on robotics. Consequently teachers, researchers, organizers of educational activities and industry have been identified as direct stakeholders [27]. They have different requirements from ER based on their needs and activities done by them [27], which are presented in Table I. All stakeholders do workshops. Teachers, researchers and organizers do activities, where they present information. Just teachers and researchers do research, and just teachers do lessons in schools. Regarding stakeholders' requirements of the activities, it is shown that most of the cases they require a good description of the activity to implement it. Just teachers and researches need activities that could be compared. On the other hand just teachers and organizers required activities that could be sustainable for long periods. The case of industry is particular because they required activities that let them promote their technologies. Although these stakeholder share some activities and their needs could be consider as complementary, there is not a good collaboration between them.

To exemplify the lack of collaboration, let's consider the case of researchers from all fields that ER converge to. In the ideal case, researchers communicate and establish common goals that are achieve through continue interaction within them. This produces ideas for new technologies and pedagogical approaches that could be used in education, which is reflected in the creation of workshops and lessons. These activities are expected to be described in enough detail that other people outside the group of work could implement. This provides several benefits: validate results, extend research beyond the original environment and use on different settings. Once the activity has been completed, researchers analyze the information collected, which brings new questions and suggestions for pedagogy and technology. Using these results as a base, researchers begin again with the cycle. However, the reality is that this collaboration between researchers is still limited or inexistent. Lets consider robotics and education researchers. In the ideal situation, they would work together to complement each other. Robotics researcher will provide the technological expertise that educational researches do not have and educational researchers will provide the knowledge to include the educational component during the design and development of robots and technologies. However, in many cases, this collaboration has been limited or inexistent.

\section{WHAT ARE THE ACTIVITIES COVERED IN EDUCATIONAL ROBOTICS?}

The study done by ER4STEM's researches on the available literature found several weaknesses on how works on ER are documented [23]. (1) There is not a clear evidence how pedagogical theories were considered during the design of the activity. (2) Activities reported in many cases are not fully described, which limit their replicability. The last situation even occurs among researchers, who do not provide a detail description of their settings such as the ones reported in [16], [17], [18], [19]. In most of the cases researchers implemented as a workshops, which usually are done as extracurricular or non-formal activity. Therefore, researchers do not include learning outcomes and evidence of learning. In other cases they are implicit but not correctly documented. As a consequence, ER4STEM's researchers suggested that workshops and lessons must be treated as similar because regarding the place where the activity is implemented is required to have a clear learning outcomes and evidence of learning. This has several benefits. (1) The activities designed and implemented as a workshop are easily implemented as a lessons. This is due the description of objectives and proof of learning, which makes easer to recognize the connection with the school's curricula. (2) The evidence of learning let people to verify if the activity achieved the expected results or not. Also it could be used to measure the real impact of ER in the short term, which is important because it has not been quantified yet [28] and it would generate arguments towards the implementation of ER activities.

Based on all of these, ER4STEM's researchers suggest to call activities done in ER as pedagogical activities with the following characteristics: (1) clear learning outcomes and evidence of learning, which could be formal (e.g. assessment) or informal (e.g. write to a friend about what you have done today). (2) Use of one or more pedagogic methodology during the activity, which has to be described for each action in the activity. This is really important because technology alone is not enough to obtain desire learning outcomes [29]. (3) Description of the activity using an activity template (e.g. ER4STEM's activity template [30]). This will help other stakeholders to have a clear idea of all considerations taken into account and the assumptions done by the designer.

\section{ER4STEM FRAMEWORK}

General speaking, stakeholders are on their own when they have to design and implement a pedagogical activity in ER. Therefore, a person must have high knowledge in technology and education to correctly implement them. However, few people have all of this knowledge. As a consequence, ER4STEM is developing a framework that will guide any stakeholder on the design or adaptation, implementation and evaluation of pedagogical activities in ER. This is achieved through the explicit connection among pedagogical methodologies, knowledge in robotics and other areas, and 21 st century skills [31].

The ER4STEM's framework provides four components. (1) An ontology of ER, which provides specific definition of words used in the field and connection between them. (2) Activity blocks, which are piece of activities that have been proven to be useful to foster specific skills and could be connected with other blocks to create a pedagogical activity. (3) Best practices, which are described from a literature reviewed done for creativity, collaboration, communication, critical thinking, evidence of learning, mixed gender teams, multiple entry points, changing and sustaining attitudes to STEM, and differentiation. (4) Processes for workshops and conferences for young people, which are based on the macroprocess depicted in Figure 2. 
TABLE I

ACTIVITIES AND NEEDS FOR EACH STAKEHOLDER WHO HAS A DIRECT IMPACT ON THE QUALITY OF ER'S ACTIVITIES [27].

\begin{tabular}{|c|c|c|c|c|}
\hline & Teachers & Researchers & $\begin{array}{l}\text { Organizers of Educational } \\
\text { Activities }\end{array}$ & Industry \\
\hline Activities & $\begin{array}{l}\text { - Workshop } \\
\text { - Presentation } \\
\text { - Research } \\
\text { - Lesson }\end{array}$ & $\begin{array}{l}\text { - Workshop } \\
\text { - Presentation } \\
\text { - Research }\end{array}$ & $\begin{array}{l}\text { - Workshop } \\
\text { - Presentation }\end{array}$ & - Workshop \\
\hline Requirements & $\begin{array}{l}\text { - Pedagogical informed de- } \\
\text { scription } \\
\text { - Compare activities and } \\
\text { results } \\
\text { - Well described activities } \\
\text { - Sustainable activities }\end{array}$ & $\begin{array}{l}\text { - Pedagogical informed de- } \\
\text { scription } \\
\text { - Compare activities and } \\
\text { results } \\
\text { - Well described activities }\end{array}$ & $\begin{array}{l}\text { - Well described activities } \\
\text { - Sustainable activities }\end{array}$ & $\begin{array}{l}\text { - Specific set of skills } \\
\text { - Promote their technologies }\end{array}$ \\
\hline
\end{tabular}

The macro-process is compound by four main macro phases. (1) The first macro phase is divided in two possible steps, which represents the possibility to design an activity from scratch or adapt one from other existing activities. (2) Implementation macro-phase focuses on considerations involving the settings and the context in which the activity is going to take place. (3) Evaluation macro-phase focus on evaluating the implementation. (4) Improvement macrophase focuses on possible improvements of the activity plan based on information derived from the implementation in real settings, on reflections from the teachers, the students and the designers. Once the activity has been improved, the cycle should be continuing with adapting the activity for future groups.

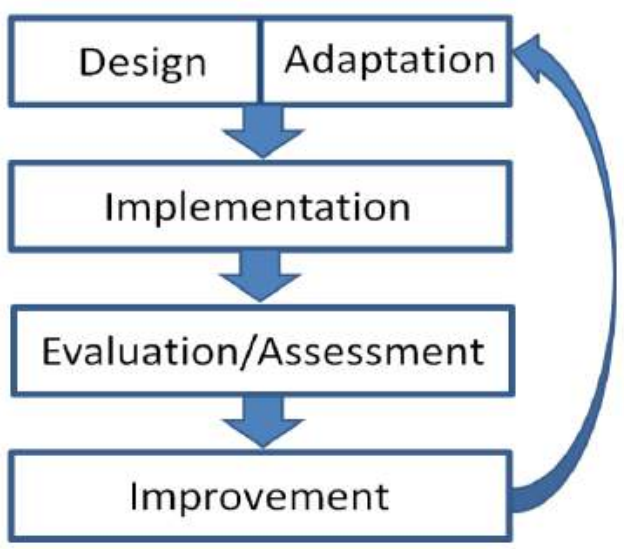

Fig. 2. Framework macro-process.

\section{WHAT FIELDS ARE INVOLVED IN EDUCATIONAL ROBOTICS?}

Based on the information provided until this point, it is possible to observed certain fields of study that are involved in ER. Figure 3 presents a simplified view of them and their interconnections. By simplified, it is meant that just general fields are depicted and other fields (e.g. artificial intelligence) are omitted, without undervalue their contribution, to increase the clarity. Three main fields are presented in the figure. (1) Education embraces all sub-fields that are related to the study and improvement of learning experiences of people at all levels, from early childhood to university. (2) Robotics is the field that studies and improve robots. A tangible result is robotics platforms that in some cases have been used in education. A good example is the robotics platform Pioneer, which is meant to be used in research but it is also used in robotics college courses. This is called robotics in education. These platforms have been designed and implemented without considering their use in education. Therefore, they provide a hundred of functionality but there is not much space to create basic activities with them, which is called in education as black box [32]. (3) Human Computer Interaction (HCI) is a field that studies the interaction between computer and humans, aiming to improve user experience. This field has shown the importance of considering humans in the design of robotics platforms. As a result the field of Human Robot Interaction (HRI) was established, which is dedicated to understand, design and evaluate robotic platforms to be used with or by humans [33].

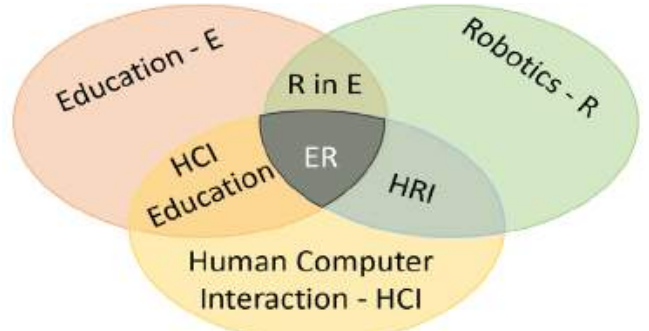

Fig. 3. A simplified view of fields of study that conformed educational robotics. Educational Robotics is the intersection between Education, Robotics and Human Robot Interaction. E means Education, R robotics, HCI Human Computer Interaction, HRI Human Robot Interaction, R in E Robots in Education, and ER Educational Robotics.

With all of this information and analysis, it is possible to conclude that ER is not just a tool but rather a field of study by its own, where many fields of study converge. Therefore, the definition of ER proposed in this article is the following: 
Educational Robotics is a field of study that aims to improve learning experience of people through the creation, implementation, improvement and validation of pedagogical activities, tools (e.g. guidelines and templates) and technologies, where robots play an active role and pedagogical methods inform each decision.

It is important to highlight that this definition covers existing categories of the use of robotics in education. Alimisis and Kynigos [4] identified two categories. (1) robotics as learning object focuses on robotic related topics, such as computer vision and artificial intelligence. (2) Robotics as learning tool sees robots as a tool to teach other subjects, such as science or math. Eguchi has proposed a third category [5] that sees robots as learning aids, which would be in most of the cases social robots, such as the Robot-Tutor in collaborative learning scenarios [34] and Robot-Tutor in teaching languages [35]. Robotic platforms in the first two categories are characterized to be cheap, and with limited number of sensors, actuators and computer processing, in comparison to its industrial counterparts. Also they are not limited to traditional programming languages (e.g. Python, $\mathrm{C}++$ and $\mathrm{C}$ ) but they used novel programming languages to improve the learning experience (e.g. Scratch [36] and tangible programming [37]). Robots in the last category are expensive due to they have to interact in a natural way with humans and behave in a way that is comfortable for humans.

\section{CONCLUSIONS}

This paper presented stakeholders and the requirements of teachers, researchers, workshops organizers and industry in ER. These requirements were used to draw the components of an activity in ER. It was suggested that there should not be difference between lessons and workshops because both must have learning outcomes and proof of learning. These would enable stakeholder to use these activities designed and implemented for workshops in lessons and vice-versa. Also, it would allow to measure the impact of robotics in education, which is still unknown [28]. Therefore the use of the tag pedagogical activity was suggested to name activities in ER, which have the following characteristics: clear learning outcomes and evidence of learning, use of one or more pedagogic methodology, and description of the activity using specific templates template(e.g. ER4STEM's activity template [30]). Also, it was presented the ER4STEM framework, which aims to guide any stakeholder on the design or adaptation, implementation and evaluation of pedagogical activities in ER. Based on all these information, it was presented the fields that converge in ER and it was suggested the following definition for ER:

Educational Robotics is a field of study that aims to improve learning experience of people through the creation, implementation, improvement and validation of pedagogical activities, tools (e.g. guidelines and templates) and technologies, where robots play an active role and pedagogical methods inform each decision.

This definition covers existing categories of the use of robotics in education: robotics as learning object [4], robotics as learning tool [4], and as leaning aid [5].

The authors hope that these definitions are used as a based to define the field of ER and the characteristics of the activities developed on it. These clear definitions will help different stakeholders to understand and apply correctly the knowledge created in the field and to strength the collaboration between different researchers and even stakeholders.

\section{ACKNOWLEDGMENT}

This work is funded by the European Commission through the Horizon 2020 Programme (H2020, Grant agreement no: 665972). Project Educational Robotics for STEM: ER4STEM. The authors would like to to thank Georg Halmetschlager for his comments.

\section{REFERENCES}

[1] S. Papert, Mindstorms: Children, Computers, and Powerful Ideas. New York, NY, USA: Basic Books, Inc., 1980.

[2] D. Catlin and M. Blamires, "The principles of educational robotic applications (era)," in Constructionism Conference, Paris, 2010.

[3] M. G. da Silva Filgueira and C. S. González González, "Pequebot: Propuesta de un sistema ludificado de robótica educativa para la educación infantil," 2017.

[4] D. Alimisis and C. Kynigos, "Constructionism and robotics in education," Teacher Education on Robotic-Enhanced Constructivist Pedagogical Methods, pp. 11-26, 2009.

[5] A. Eguchi, "Educational robotics theories and practice: Tips for how to do it right," Robotics: Concepts, Methodologies, Tools, and Applications: Concepts, Methodologies, Tools, and Applications, vol. $193,2013$.

[6] S. Atmatzidou and S. Demetriadis, "A didactical model for educational robotics activities: A study on improving skills through strong or minimal guidance," in International Conference EduRobotics 2016. Springer, 2016, pp. 58-72.

[7] F. Agatolio, M. Pivetti, S. Di Battista, E. Menegatti, and M. Moro, "A training course in educational robotics for learning support teachers," in International Conference EduRobotics 2016. Springer, 2016, pp. 43-57.

[8] D. Alimisis, "Robotics in education \& education in robotics: Shifting focus from technology to pedagogy," in Proceedings of the 3rd International Conference on Robotics in Education, 2012, pp. 7-14.

[9] L. Lammer, A. Weiss, and M. Vincze, "The 5-step plan: A holistic approach to investigate children's ideas on future robotic products," in Proceedings of the Tenth Annual ACM/IEEE International Conference on Human-Robot Interaction Extended Abstracts. ACM, 2015, pp. 69-70.

[10] C. Wegner, F. Strehlke, and P. Weber, "Investigating the differences between girls and boys regarding the factors of frustration, boredom and insecurity they experience during science lessons," Themes in science and technology education, vol. 7, no. 1, pp. 35-45, 2014.

[11] D. Tochek, J. Lape, and V. Fuglk, "Developing technological knowledge and programming skills of secondary schools students through the educational robotics projects," Procedia - Social and Behavioral Sciences, vol. 217, pp. 377 - 381, 2016.

[12] J. Ashdown and D. Doria, "A robotics based design activity to teach the doppler effect." in IEEE 2nd Integrated STEM Education Conference. IEEE, 2012.

[13] S. Hussain, J. Lindh, and G. Shukur, "The effect of lego training on pupils' school performance in mathematics, problem solving ability and attitude: Swedish data," Journal of Educational Technology \& Society, vol. 9, no. 3, 2006.

[14] J. M. Angel-Fernandez and M. Vincze, "Introducing storytelling to educational robotic activities," in Proceedings of EDUCON2018 IEEE Global Engineering Education Conference. IEEE, 2018.

[15] J. Sharkey, "Establishing twenty-first-century information fluency," Reference \& User Services Quarterly, vol. 53, no. 1, p. 33, 2013.

[16] A. Sullivan and M. U. Bers, "Robotics in the early childhood classroom: learning outcomes from an 8-week robotics curriculum in pre-kindergarten through second grade," International Journal of Technology and Design Education, vol. 26, no. 1, pp. 3-20, 2016. 
[17] A. Sullivan, E. R. Kazakoff, and M. U. Bers, "The wheels on the bot go round and round: Robotics curriculum in pre-kindergarten," Journal of Information Technology Education, vol. 12, 2013.

[18] K. Stoeckelmayr, M. Tesar, and A. Hofmann, "Kindergarten children programming robots: a first attempt," Proc. Robotics in Education, pp. 185-192, 2011.

[19] W. J. Church, T. Ford, N. Perova, and C. Rogers, "Physics with robotics - using lego mindstorms in high school education." in AAAI Spring Symposium: Educational Robotics and Beyond. AAAI, 2010.

[20] E. Walker and W. Burleson, "User-centered design of a teachable robot," in International Conference on Intelligent Tutoring Systems. Springer, 2012, pp. 243-249.

[21] L. N. Brown and A. M. Howard, "The positive effects of verbal encouragement in mathematics education using a social robot," in Integrated STEM Education Conference (ISEC), 2014 IEEE. IEEE, 2014, pp. 1-5.

[22] G. Castellano, I. Leite, A. Paiva, and P. W. McOwan, "Affective teaching: learning more effectively from empathic robots," 2012.

[23] J. M. Angel-Fernandez, L. Lammer, C. Kynigos, I. Gueorguiev, P. Varbanov, W. Lepuschitz, A. Duca, J. Pullicino, M. Grizioti, S. Nikitopoulou, C. Girvan, and P. Vrba, "Best practice and requirements," TU Wien, University of Athens, ESI, Cardiff University, AcrossLimits and Certicos," Deliverable, 2016.

[24] F. E. Digital, "Competencias digitales en españa como mejorarlas?" Internet, www.espanadigital.org, 2015.

[25] Eurydice, "The teaching profession in europe: Practices, perceptions, and polices," Internet, 2015.

[26] M. Caprile, R. Palmén, P. Sanz, and G. Dente, "Encouraging stem studies: Labour market situation and comparison of practices targeted at young people in different member states," European Parliament's Committee on Employment and Social Affairs, 2015.

[27] J. M. Angel-Fernandez, C. Kynigos, W. Lepuschitz, J. Pullicino, M. Grizioti, C. Girvan, and C. Todorova, "Towards an extended definition of er4stem framework," TU Wien, University of Athens, ESI, Cardiff University and AcrossLimits," Deliverable, 2017.
[28] F. B. V. Benitti, "Exploring the educational potential of robotics in schools," Comput. Educ., vol. 58, no. 3, pp. 978-988, Apr. 2012.

[29] C. Richards, "Towards an integrated framework for designing effective ict-supported learning environments: the challenge to better link technology and pedagogy," Technology, Pedagogy and Education, vol. 15, no. 2, pp. 239-255, 2006.

[30] N. Yiannoutsou, S. Nikitopoulou, C. Kynigos, I. Gueorguiev, and J. A. Fernandez, "Activity plan template: a mediating tool for supporting learning design with robotics," in Robotics in Education. Springer, 2017, pp. 3-13.

[31] P. P. for 21st Century Learning, "Framework for 21st century learning," Internet, http://www.p21.org/our-work/p21-framework.

[32] C. Kynigos, "Black-and-white-box perspectives to distributed control and constructionism in learning with robotics," in Proceedings of SIMPAR workshops, 2008, pp. 1-9.

[33] M. A. Goodrich and A. C. Schultz, "Human-robot interaction: A survey," Found. Trends Hum.-Comput. Interact., vol. 1, no. 3, pp. 203-275, Jan. 2007. [Online]. Available: http://dx.doi.org/10.1561/1100000005

[34] P. Alves-Oliveira, S. Janarthanam, A. Candeias, A. Deshmukh, T. Ribeiro, H. Hastie, A. Paiva, and R. Aylett, "Towards dialogue dimensions for a robotic tutor in collaborative learning scenarios," in Robot and Human Interactive Communication, 2014 RO-MAN: The 23rd IEEE International Symposium on. IEEE, 2014, pp. 862-867.

[35] T. Belpaeme, P. Vogt, R. van den Berghe, K. Bergmann, T. Göksun, M. de Haas, J. Kanero, J. Kennedy, A. C. Küntay, O. OudgenoegPaz, et al., "Guidelines for designing social robots as second language tutors," International Journal of Social Robotics, 2017.

[36] M. Resnick, J. Maloney, A. Monroy-Hernández, N. Rusk, E. Eastmond, K. Brennan, A. Millner, E. Rosenbaum, J. Silver, B. Silverman, and Y. Kafai, "Scratch: Programming for all," Commun. ACM, vol. 52, no. 11 , pp. $60-67$, Nov. 2009

[37] M. U. Bers and M. S. Horn, "Tangible programming in early childhood," High-tech tots: Childhood in a digital world, vol. 49, pp. 49-70, 2010. 